\title{
Spatial distribution and stratigraphic characteristics of surface sediments in Taihu Lake, China
}

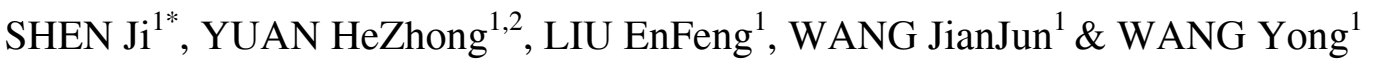 \\ ${ }^{1}$ State Key Laboratory of Lake Science and Environment, Nanjing Institute of Geography and Limnology, Chinese Academy of Sciences, Nanjing \\ 210008, China; \\ ${ }^{2}$ Graduate University of the Chinese Academy of Sciences, Beijing 100049, China
}

Received May 4, 2010; accepted September 30, 2010

\begin{abstract}
A geophysical survey was carried out for Taihu Lake, one of the largest shallow lakes in China. The StrataBox ${ }^{\mathrm{TM}}$ Marine Geophysical Instrument was applied for the first time to obtain high-resolution seismic data (in the form of vectorgraphs) of the lake sediment. Data were then interpreted by SonarWiz.Map acoustics software. Data were correlated with core stratigraphy from the lake as well as an outcrop on the northern side of the lake at Yao Bay. Results show that the upper $10 \mathrm{~m}$ sediment (beneath the interface of the sediment and the overlying lake water) is characterized by laminated sediments, which can be classified into two stratal types, i.e. lacustrine sediment stratum (U1) and underlying hard loess stratum (U2). The contact of these two lithologies is not continuous, and part of it is absent in the lake basin. Unequally spread over the lake basin, the lacustrine sediment (mainly consisting of sludge and muddy-clay) is found in areas along the western bank, to the northwest of the Xishan Mountains and along the northwestern side of the lake. In the rest of the lake basin, the hard loess stratum is exposed in outcrops. The depth of the lacustrine sediment ranges from 1 to $2 \mathrm{~m}$, while the depth of the sludge (closely related to the modern lacustrine environment) varies from 0.03 to $1.0 \mathrm{~m}$. The spatial distribution of lacustrine sediments in Taihu Lake is primarily influenced by transportation and sedimentation of riverine materials, as well as the hydrodynamics of lake currents.
\end{abstract}

surface sediment, spatial distribution, stratigraphy, geophysical survey, Taihu Lake

Citation: Shen J, Yuan H Z, Liu E F, et al. Spatial distribution and stratigraphic characteristics of surface sediments in Taihu Lake, China. Chinese Sci Bull, 2011, 56: 179-187, doi: 10.1007/s11434-010-4214-0

The Taihu Lake is an archetypal large freshwater lake in the middle and lower reaches of the Yangtze River in China. This lake is experiencing severe eutrophication [1,2]. Thus, considerable efforts have been made over many years to research and manage the hydrological environments of Taihu Lake. For example in 2007, an extensive algal bloom caused a drinking water supply crisis in the city of Wuxi, which prompted residents to address the problem [3]. Recent studies [4-6] show there is a close relationship between nutrient concentrations of the lake water and spatial distribution of lake sediment. In addition, there appears to be a correlation between the spatial distribution of algal blooms and sediment $[7,8]$. However, limitations in underwater

*Corresponding author (email: jishen@niglas.ac.cn) geophysics and bathymetry technologies have prevented elucidation of the spatial distribution and bathymetry of surface sediment in Taihu Lake.

In the late 1980s, Sun and Wu [9] surveyed the stratigraphy of the Taihu Lake basin with a GPY sub-bottom profiler, to determine the basic tectonic structure of the lake basin. Fan et al. [10] measured sediment depth with a pressure bar and qualitatively obtained the spatial distribution of sediments over the entire lake. Jia and Yuan [11] surveyed sediment distribution in the lake with a Holand SILAS Sub-bottom Sediment Characterization System, but only for Meiliang, Zhushan and Gonghu bays. To obtain accurate data on spatial distribution of sediments for the entire lake, we carried out a high-resolution geophysical survey on Taihu Lake over a period of more than four months. The 
acquired seismic data (in the form of vectorgraphs) were interpreted in the lab by SonarWiz.Map acoustics software, to reveal reflection characteristics of the acoustic profiles of the sediments. These were later correlated with stratigraphy of available sediment cores and previous geological surveys, and the stratigraphic sequences of our in situ drilled sediment cores, in order to obtain information on the spatial and temporal variations in stratigraphy of the sediments in Taihu Lake. Our work provides valuable information regarding: 1) spatial distribution of the sediments in Taihu Lake; 2) accurate estimation of the load of inner contamination of the lake; and 3) feasibility of a proposal to dredge sludge from the lake in the near future.

\section{Materials and methods}

A bathymetric survey of lake water over the entire lake was first complemented with a Hondex (USA) Digital Sonar. Sediment stratigraphy data were obtained with a StrataBox ${ }^{\mathrm{TM}}$ Marine Geophysical Instrument (Ocean Data Equipment Corporation, USA). This instrument was invented for inshore and coastal geophysical surveys [12,13] as a kind of low-power-consuming portable underwater instrument (specifications: strata resolution of $6 \mathrm{~cm}$ with $40 \mathrm{~m}$ of bottom penetration; maximum depth range of $150 \mathrm{~m}$; frequency output of $10 \mathrm{kHz}$ ). This is the first time that this instrument has been used to investigate stratigraphy of Chinese lake sediments. The instrument was fixed on a medium-sized vessel (tonnage of $10 \mathrm{t}$ and hull length of $10 \mathrm{~m}$ ), and the velocity of the ship was manipulated between 6-8 $\mathrm{km} / \mathrm{h}$ when surveying the top $10 \mathrm{~m}$ of the sediment. A Trimble DSM 232 GPS (Trimble Navigation Limited, USA) was used for positioning, and yielding synchronous GPS data with the seismic data.

A total of $130^{\circ} \mathrm{E}-\mathrm{W}$ directional survey lines were undertaken over the extent of Taihu Lake (Figure 1), with the distance of ca. $1 \mathrm{~km}$ between every other survey line. Bathymetric data were recorded with StrataBox ${ }^{\mathrm{TM}}$ hydrographic software and vectorgraphs were displayed and stored in a laptop computer. Geophysical surveys were carried out during October to December, 2008 and April to June, 2009. In the laboratory, we used the SonarWiz.MAP acoustic software package to acquire synchronized data of longitude, latitude and depth with a resolution of 1-2 km (Figure 1).

Using a Kajak coring instrument (Plexiglas cylinder tubes with the diameter of $8 \mathrm{~cm}$ ), we also retrieved more than 100 sediment cores from different areas throughout the Taihu Lake, with distinct sediment lithologies. The sediment cores were used to test seismic data and to help interpret vectorgraphs. The length of the acquired cores ranged from 30 to $150 \mathrm{~cm}$, except for cores (only $5 \mathrm{~cm}$ in length) retrieved from the southern and eastern parts of the lake.

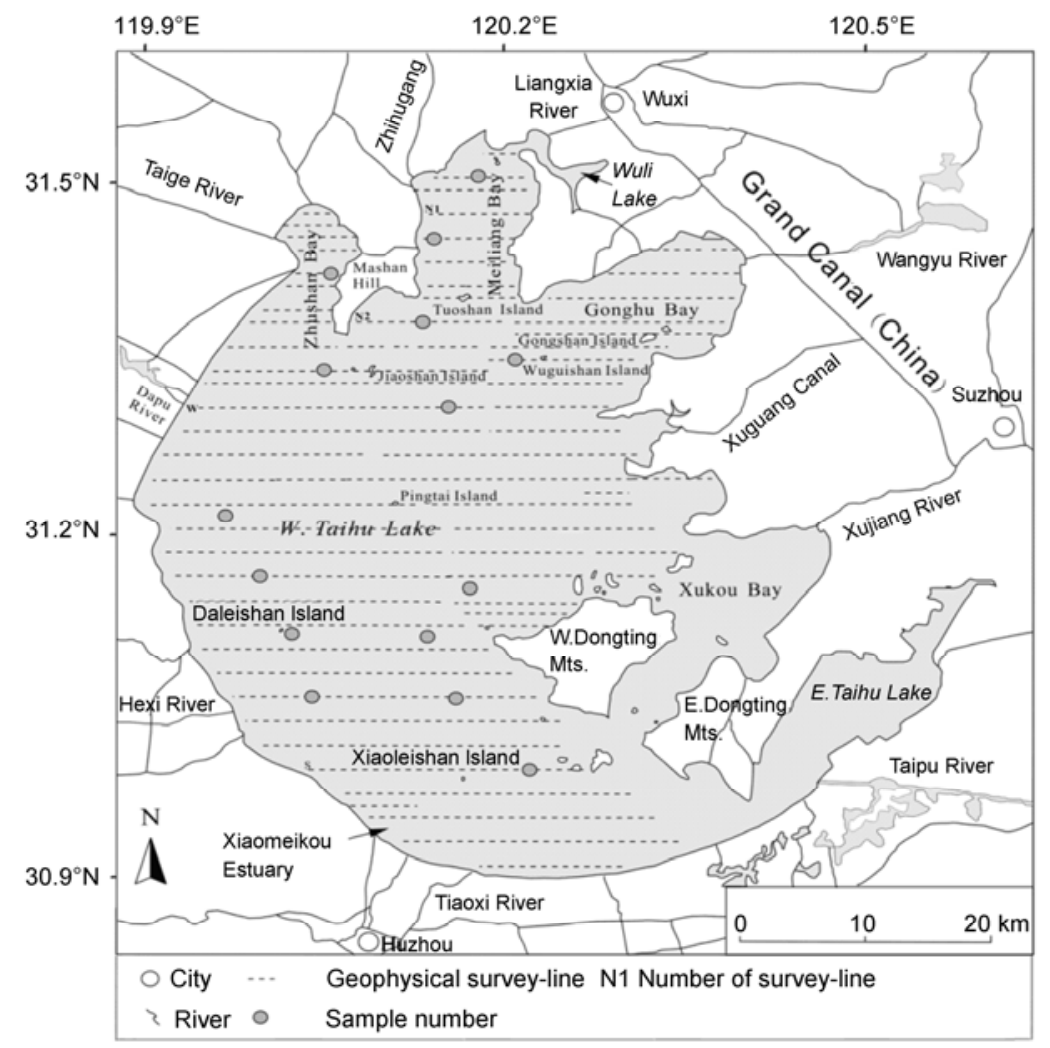

Figure 1 Survey lines (denoted by dashed lines) for geophysical investigation and core sites at the Taihu Lake. 
Some of the sediment cores contained the stratum of the Xiashu loess, which has been shown to be widely distributed in the lake basin. A set of 15 cores from 15 typical locations (Figure 1) were cut into $1 \mathrm{~cm}$ slices for the upper 30 $\mathrm{cm}$ section, and into $2 \mathrm{~cm}$ slices for the section beneath a depth of $30 \mathrm{~cm}$. The split sediment samples were sealed in polythene bags and stored below $4^{\circ} \mathrm{C}$. Analyses of water content $(\Phi)$ and bulk density $(\gamma)$ were conducted for all samples. Samples of the corresponding overlying water also were collected from the above 15 sites to determine total nitrogen (TN) and total phosphorus (TP) concentrations.

\section{Results and discussion}

\subsection{Water bathymetry of Taihu Lake}

Figure 2 illustrates the relief map for Taihu Lake (exclusive of the eastern lake and the Wuli Lake), based on 1590 groups of data obtained by digital sonar. The figure shows that the water depth ranged between 2.2 and $3.0 \mathrm{~m}$, with an average depth of $2.6 \mathrm{~m}$ for the entire lake, $2.1 \mathrm{~m}$ for Zhushan Bay, $2.3 \mathrm{~m}$ for the Meiliang Bay and $2.4 \mathrm{~m}$ for the Gonghu Bay. The shape of the lake basin is acetabuliform. From brim to the center of the lake, water depth increases to a maximum of $3.4 \mathrm{~m}$. Compared with previous data [1], our water depth results of Taihu Lake reveal more precise underwater topography characteristics. The entire lake basin is relatively flat, with sporadic subaqueous islands and troughs only found in small areas of the lake. Notable is that deep water occurs along the water traffic areas, such as the shipping channel striking from the estuary of the Tiaoxi River (to the northwest of the Xishan Mountain) to the estuary of the Wangyu River (in the northeast of the Gonghu Bay). This is the main waterway linking Huzhou (south of Taihu Lake) to the Grand Canal (northeast of Taihu Lake). This indicates that human activities (including shipping) exert considerable influence on the underwater topography of Taihu Lake.

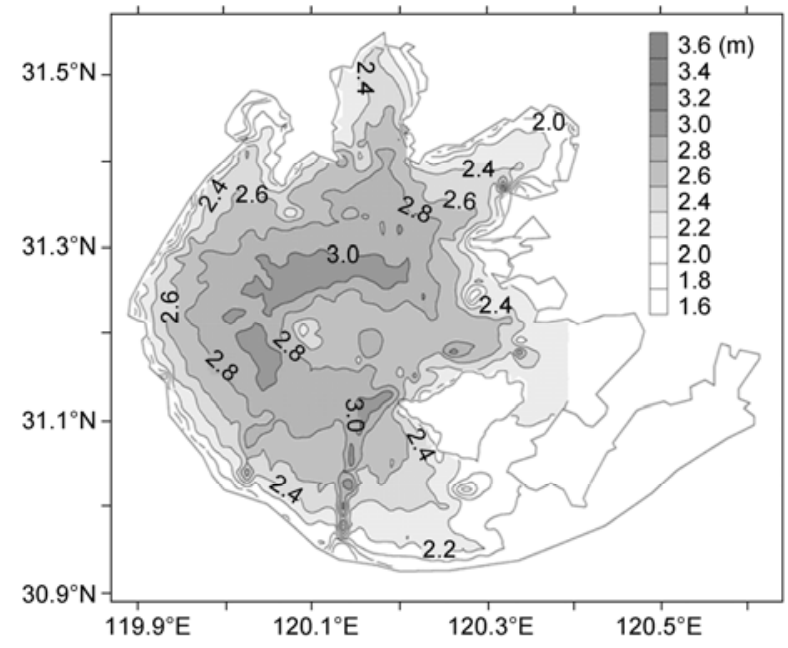

Figure 2 Contour plot of water depth of Taihu Lake.

\subsection{Seismic facies and stratigraphy of sediments of Taihu Lake}

To interpret the obtained seismic data, we complemented correlations between the seismic vectorgraphs and the corresponding sediment stratigraphy. The left panel of Figure 3 illustrates an outcrop in Yao Bay (north of Meiliang Bay) after its embanking and draining in 2007. The stratigraphy of the northern basin of Taihu Lake is summarized from outcrop data (Figure 3(a)). Also illustrated in Figure 3 are three additional sections from near Mashan Hill [14] (Figure 3(b)), eastern Taihu Lake [15,16] (Figure 3(c)) and southern lake areas (Figure 3(d)), respectively. Based on inter-correlations of seismic vectorgraphs and corresponding sediment stratigraphy for the same sites, the stratigraphy for the whole lake is defined. According to the seismic facies results, the stratigraphy consists of 4 layers (denoted by I2, I1, I3 and I4). The topmost I1 layer is the interface of lake water and sediment. The top $10 \mathrm{~m}$ section of the lake sediment is composed of 4 layers (denoted by $\mathrm{U} 1, \mathrm{U} 2, \mathrm{U} 3$ and $\mathrm{U} 4$ ) (Figures 4-8).
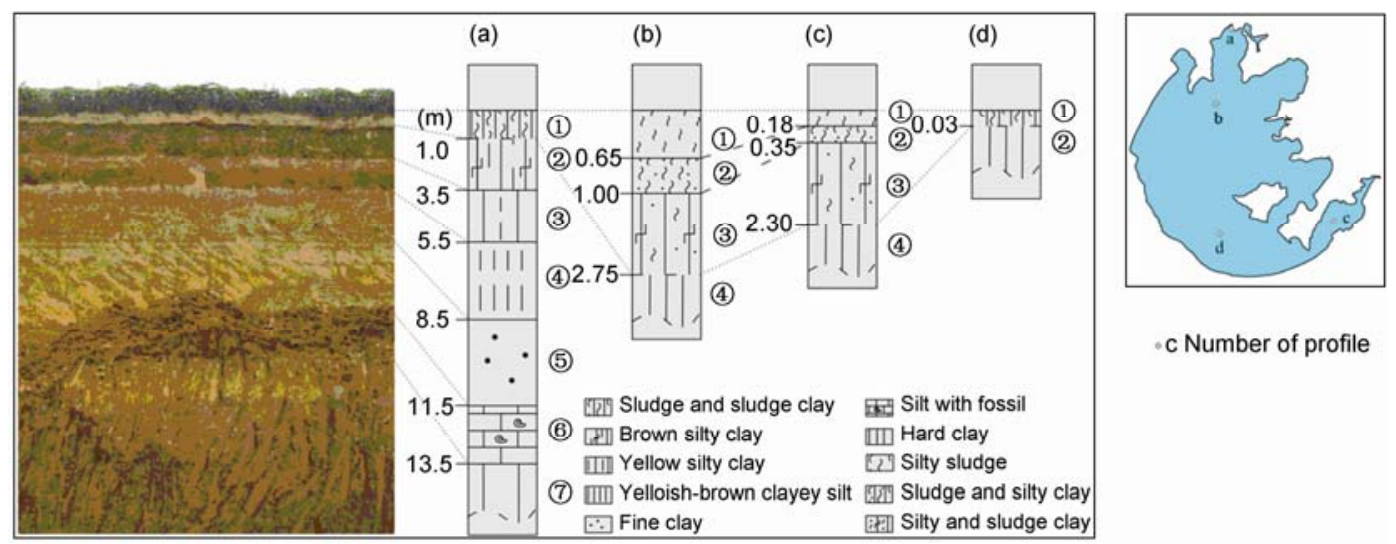

Figure 3 Profiles of sediment cores and their correlations with stratigraphy. (1)-(7) show the correlations of the stratigraphy. 
(i) Unit 1. This stratum is the most recent sediment, and is located between the upper layer I1 and the lower hard loess layer, consisting mainly of Quaternary lacustrine gray-blackish deposits. Laminated sediments (with alternating coarse grain layers and thin grain layers) are mainly notable in the lower section of this stratum, due to relatively stable sedimentation. Stratum U1 is widely distributed in the western and northwestern part of Taihu Lake. However, in eastern and southern parts of the lake, the thickness of U1 is less and its distribution is limited with respect to the underlying loess layer (U2) cropping out in some areas. Based on variations in water content, unit 1 can be further classi- fied into 2 subunits, i.e. a sludge layer (U1-I) and a silty-clay layer (U1-II). The sludge layer generally is considered as an important object of limnological study (e.g. sediment pollution and sediment biogeochemistry) $[17,18]$. This is because this layer often interacts with the overlying lake water, giving rise to complicated biogeochemistry processes, and because it is both the pool and source for pollutants and nutrients.

(ii) Unit 2. This stratum mainly is made up of hard brown-yellowish loess, and strong seismic signals indicate that this layer is extensively distributed in Taihu Lake. The stratum crops out over considerable areas in the middle and

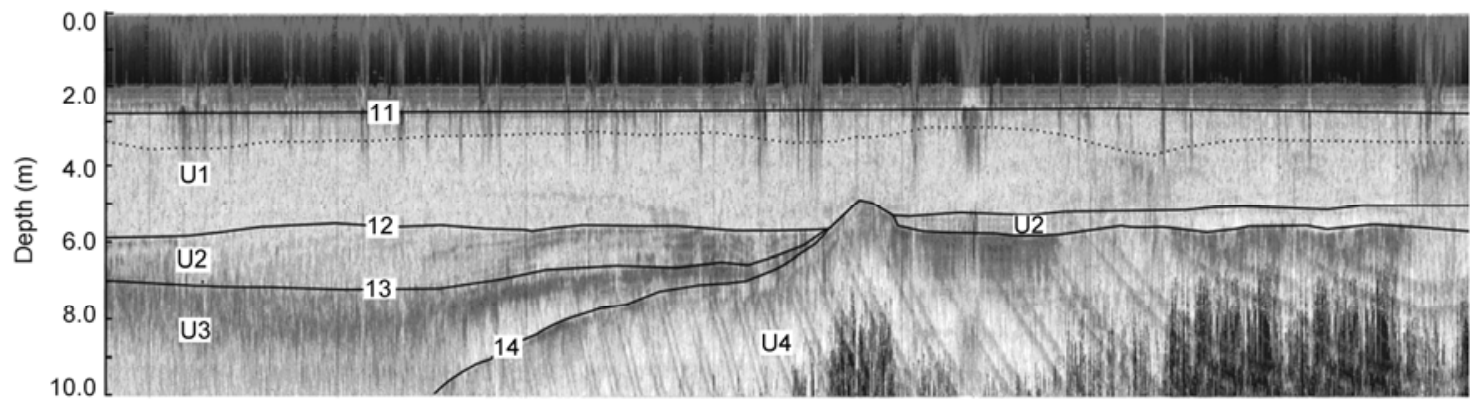

Figure 4 Stratigraphy of the sediments along the survey line N1 in the Meiliang Bay. The solid lines denote boundaries between strata, and the dotted lines denote the boundary between the sludge stratum and the silty clay stratum. Note that the dotted lines do not indicate the seismic facies with clear difference in stratigraphy, but represent the dividing line between the two strata which are relevant to different conditions of the modern environment. I1 is the corrected sediment-water interface defined by the seismic data for surface sediment, with the diffuse reflection removed.

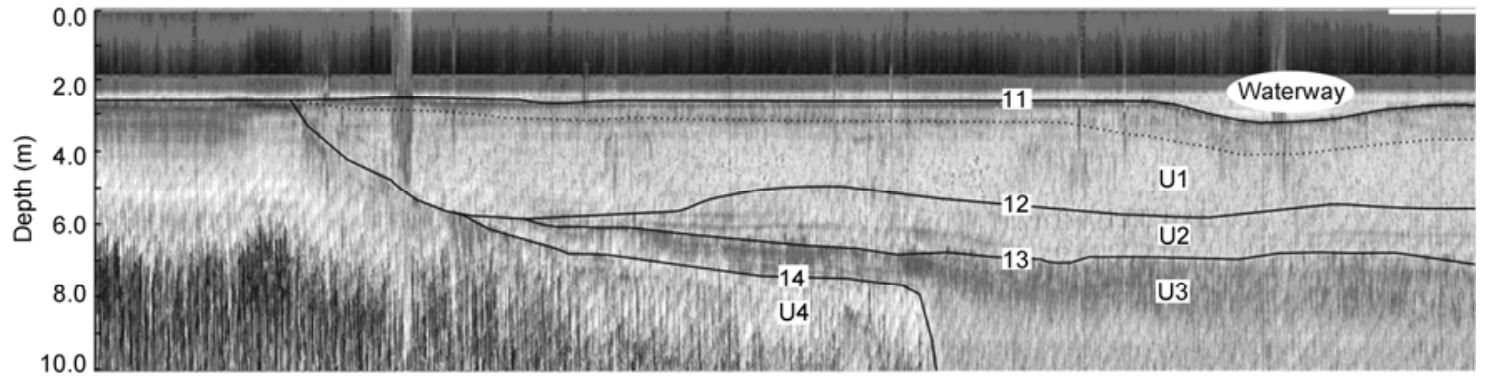

Figure 5 Stratigraphy of sediments along survey line N2 near Mashan Mountain in the Meiliang Bay.

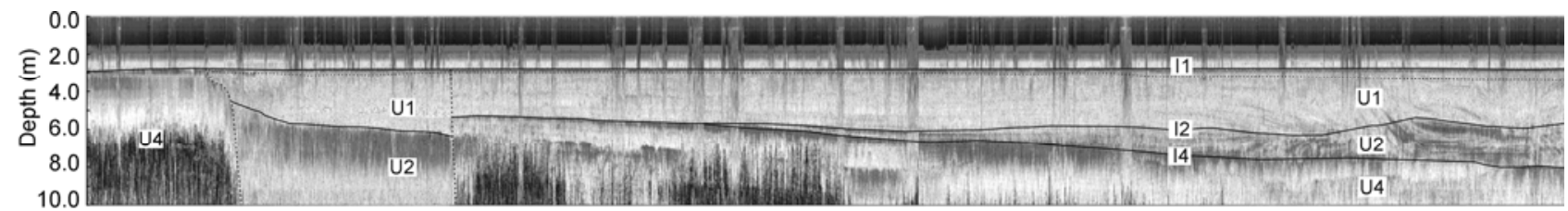

Figure 6 Stratigraphy of sediments along the survey line W near Dapu Estuary in western Taihu Lake. The dotted lines denote palaeo-riverways.

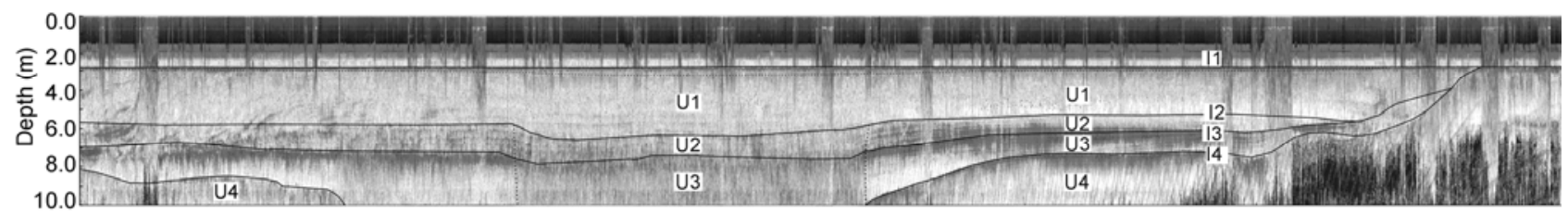

Figure 7 Stratigraphy of sediments along the survey line W near Dapu Estuary in the western Taihu Lake (near the center of the lake). The dotted lines denote the palaeo-riverways. 


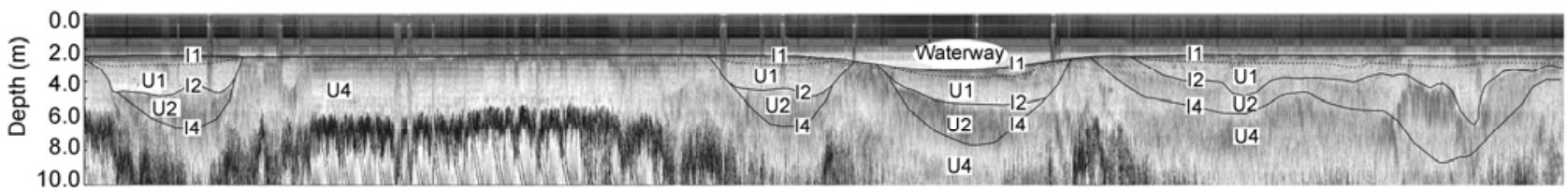

Figure 8 Stratigraphy of sediments along the survey line S in the southern Taihu Lake.

eastern parts of the lake, but it dives gradually under U1 towards the west of the lake. The top of this stratum is coated with a layer rich in iron-manganese concretions [19], constituting the bed of the lake's lacustrine deposits. The contact between $\mathrm{U} 1$ and $\mathrm{U} 2$ is not continuous (Figure 3 ). In other words, the U1 stratum does not extend all around the lake basin, but the U2 stratum is present in its entirety in the 15-m section of Yao Bay, the 2.8-m sediment core from the western side of the Lake, the 2.4-m sediment core from the eastern end of the lake, and the 5-cm sediment core from the southern part of the lake (Figure 3(a)-(d)). William et al. [16] dated the lacustrine and loess samples from U1 and U2, and found that their ${ }^{14} \mathrm{C}$ ages were approximately 6500 a BP, and ca. $15885 \pm 170$ a BP, respectively. These ages, along with data from other chronology studies [14,15] indicate that the lacustrine sediments were deposited long after the loess stratum developed.

(iii) Unit 3. This stratum is defined by relatively strong seismic signals and it is composed mainly of gray-yellowish clay with quasi-horizontal laminations. The thickness of U3 is not uniform, with maximum vertical thickness observed in the centre of Taihu Lake. The thickness of this stratum pinches toward the slope of U4. For some parts of the lake, this stratum is absent, indicating the discontinuity of the depositional environment in the lake, most probably due to secondary erosion subsequent to the deposition.

(iiii) Unit 4. Only the upper section of this stratum is defined by strong seismic signals, and mainly encompasses of gray-yellowish silty laminated sediment. For some parts of Taihu Lake, this stratum is in direct contact with U1, with U2 and U3 missing in between. Plenty of marine shelly fossils were found in the lower section of U4, suggesting sea transgressions during this time interval.

\subsection{Spatial distribution of lacustrine sediment in Taihu Lake}

The lacustrine sediment of the Taihu Lake is the most recent sediment to have been deposited, and its depth and distribution are influenced by factors such as distribution of inlet runoffs, charging flux of earth materials, and water mobility. Hence, revealing the lake's distribution of lacustrine sediments is of great significance to understanding the accumulation and transference of pollutants in sediments. In addition, the lacustrine sediments, especially within the uppermost parts, are typified by high porosity, which allows frequent exchanges of materials with the overlying water column. Therefore, lacustrine sediments act not only as the initial sinking pools for allogenetic pollutants (including nutrients, from either inflowing runoffs or from atmospheric deposition), but also as the source for internal release of nutrients. Based on studies by Søndergaard et al. [20], the phosphorus concentration in lake sediments is normally 100 times as much as that in lake water. Therefore, the release of nutrients from the sediment to lake water often takes place, especially when the sediment is disturbed by physical, chemical or biological activities.

Subsequent to the secondary consolidation of sediments, the values of down-core proxies (including water content, bulk density, porosity, and organic matter content) usually show decreasing trends. According to the "Criterion for Groundwork of Port Engineering (JTJ 250-98 ${ }^{1)}$ )", the lacustrine sediment (U1) can be classified by the proxy of water content $(\Phi)$ into two sub-units: a sludge sub-unit $(\Phi>55 \%$, U1-I) and a muddy-clay sub-unit $(55 \%>\Phi>26 \%$, U1-II). The boundary between U1-I and U1-II is denoted by dotted lines in Figures 4-8. The seismic and GPS data of our geophysical survey were interpreted by the SonarWiz.Map software package into synchronous data of longitude, latitude and depth. In total, we obtained more than $3.5 \times 10^{4}$ groups of synchronous data of longitude, latitude and depth for the lacustrine sediment of the lake and $4.2 \times 10^{4}$ groups of synchronous data for the sludge sediment of the lake. These data are shown in the contour plot (Figure 9) produced by the Surfer 8.0 software. According to the plot, the spatial distribution of the lacustrine sediments of Taihu Lake is characterized by the following features:

(i) For the middle and eastern parts of the lake, outcrops of the hard loess strata were present. Only in minor areas of the lake were the outcrops of hard loess overlain by a layer of mud $(<3 \mathrm{~cm})$. The lacustrine sediments were mainly distributed in the western and northwestern parts of the lake. In northern parts, the sediments extended first eastwards from Zhushan Bay in the north along the northern bank to the Mashan Mountains, and then southwards to $31.3^{\circ} \mathrm{N}$. The southern area of lacustrine sediments was characterized by two wings. One wing stretched from Dalei Island (at $31.1^{\circ} \mathrm{N}$ ) and eastwards to Xishan Island. In addition, it included Xishan Island and its adjacent islands in the north. The other wing spread from the Dalei Island westwards to the Xiaomeikou (the estuary of the Tiaoxi River). The average sediment depth for the entire lake was ca. $0.7 \mathrm{~m}$, close

1) The Ministry of Transport of the People's Republic of China. The Criterion for Soil Foundation of Port Engineering, 1998. 

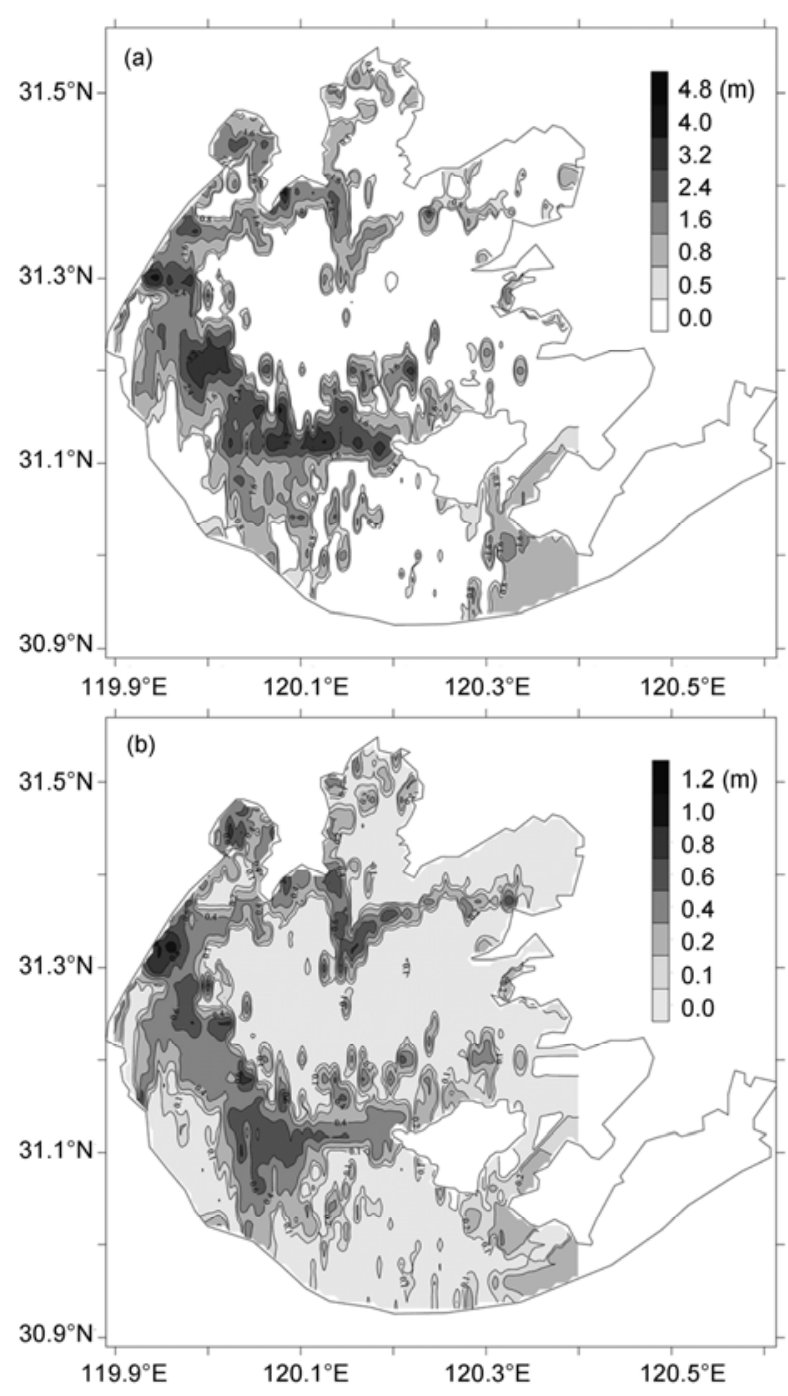

Figure 9 Contour plots of the distribution of the lacustrine sediments (a) and sludge (b) in Taihu Lake.

to the sediment depth (about $0.82 \mathrm{~m}$ ) estimated by Fan et al. [10]. However, for areas with lacustrine sediments, the average sediment depth was ca. $1.9 \mathrm{~m}$, which is much higher than the depth of $1.17 \mathrm{~m}$ measured by Fan et al. [10] in 2000. Lacustrine sediments were only found sporadically in the remaining areas of the lake. This pattern contrasts dramatically with that observed in the western part of lake and the regions from the Dalei Mountains to the Xishan Mountains, where lacustrine sediments were widely distributed. The depth of the lacustrine sediments in these areas ranged from 1 to $2 \mathrm{~m}$, with a maximum of $5 \mathrm{~m}$ occurring near the Dapu Estuary.

(ii) The distribution of lacustrine sediments differs in the northern bays of Taihu Lake. For Zhushan Bay, lacustrine sediments were widespread, with an average depth of ca. $1.8 \mathrm{~m}$, except for its middle part. For Meiliang Bay, lacustrine sediment was mainly distributed in western and northern areas, with sediment depth averaging ca. $1.4 \mathrm{~m}$. This was very close to the depth of $1.5 \mathrm{~m}$ determined by Fan et al. [10], but the average depth for the entire area of the bay was only $0.4 \mathrm{~m}$, which was much lower than the depth of $0.75 \mathrm{~m}$ determined by Fan et al. [10]. This discrepancy probably is due to sediment dredging in the bay that may have occurred after the study by Fan et al. [10]. For Gonghu Bay, lacustrine sediments were distributed only in a small area around the Gongshan Mountains, with most of the area typified by hard loess outcrops. The average sediment depth was about $1 \mathrm{~m}$, but for the entire bay it was about $0.3 \mathrm{~m}$.

(iii) The depth of the sludge subunit in Taihu Lake varied from 0.03 to $1.0 \mathrm{~m}$. This layer often tended to float and drift away, especially when disturbed by waves, making it very easy to be re-suspended from the lake bottom. This dynamic makes for very complicated biogeochemical processes, since this habitat also harbors microbes. The overall distribution of the sludge was identical to that of the lacustrine sediments, with a maximum depth of ca. $1.2 \mathrm{~m}$, as observed near the Dapu Estuary. Its water content was above 55\%, which agrees with values from other lake sediments [20]. The nutrient concentrations were much higher than those of the overlying water. For example, in the Dapu Estuary, TP content was as high as $657.0 \mathrm{mg} / \mathrm{kgdw}$, while the TP content of the overlying water was only $0.06 \mathrm{mg} / \mathrm{L}$. The concentration of $\mathrm{PO}_{4}{ }^{3-}$ (ingested by biological organisms) in the pore water of the surface $2-\mathrm{cm}$ of sediments was $0.26 \mathrm{mg} / \mathrm{L}$, while the concentration in the overlying water was 0.02 $\mathrm{mg} / \mathrm{L}$. As a large shallow lake, the hydrology of Taihu Lake and biogeochemical processes are very complicated, allowing nutrients in the sediment to be released readily to the overlying water column due to the concentration gradient $[21,22]$. This can further result in very severe eutrophication of the lake water. Thus, defining the sludge subunit is of great importance to studies of environmental ecology.

\subsection{Spatial distribution of lacustrine sediments of Taihu Lake and its relationship to inflowing rivers and lake currents}

Sun and $\mathrm{Wu}$ [9], William et al. [23] and Liu and $\mathrm{Wu}$ [24] conducted ${ }^{210} \mathrm{~Pb},{ }^{14} \mathrm{C}$ and ${ }^{137} \mathrm{Cs}$ dating on surface sediments from open areas of western Taihu Lake, near Mashan Mountain (northwest side of the lake) and near Dapu Estuary (western side of the lake). These studies showed that the sedimentation rates were $0.4,0.3$ and $1.4 \mathrm{~mm} / \mathrm{a}$, respectively, with a much higher sedimentation rate in the estuary. Suspended materials in the inflowing rivers generally deposit quickly when transported into the lake, due to extension of the water surface and reduction in hydrodynamics. Thus, sedimentation rate normally is much higher in the estuary than in the central lake, resulting in much deeper sediment layers along the lake's banks than in the middle of the lake. The inlet runoffs of Taihu Lake (e.g. Tiaoxi, Nanxi and Taige drainage systems) are all situated to the west of the lake. Spatial distribution of lacustrine sediments was 
largely identical to the spatial distribution of the river estuaries (Figure 9).

The other factor influencing spatial distribution of the lacustrine sediments was the prevailing southeasterly winds in summer, when the discharge of terrestrial materials also is highly associated with strong hydrodynamics. Given the immensity of the lake surface [5], the prevailing northwestward winds give rise to an anticlockwise lake current within the lake (Figure 10) [25], with a maximum flow velocity of $30 \mathrm{~cm} / \mathrm{s}$. In addition, there are various scales of small lake currents. For example, in the northern estuaries of the lake, the lake currents are very complex and unstable due to complicated underwater topography. Being a shallow lake, the wave amplitude of the currents is often larger than the water depth. Terrestrial materials are generally transported and deposited along stretches of the underwater topography, as well as along the routes of lake currents. Thus, terrestrial materials are not easily deposited in the center of the lake, which results in exposures of hard loess strata. Conversely, for the western part of the lake and areas around the Xishan Mountains, it is easy for terrestrial materials to be deposited, due to wind-driven lake currents along the banks. These dynamics result in accumulation of sediments. Similarly, small-scale lake currents also remove lacustrine sediments at some sites in the lake, and promote scattered distributions of sediments for other sites in the lake. Overall, the spatial distribution of lacustrine sediments is notably influenced by the coupling effects of topography of the lake basin (with elevation of the western lake basin lower than that of the eastern lake basin) and lake hydrodynamics.

\subsection{Palaeo-riverways and depressions in Taihu Lake}

According to the underwater topography and stratigraphy revealed by the seismic data, the recent laminated lacustrine sediments (indicated by stable seismic signals) were widely distributed, except for in the middle and the eastern and

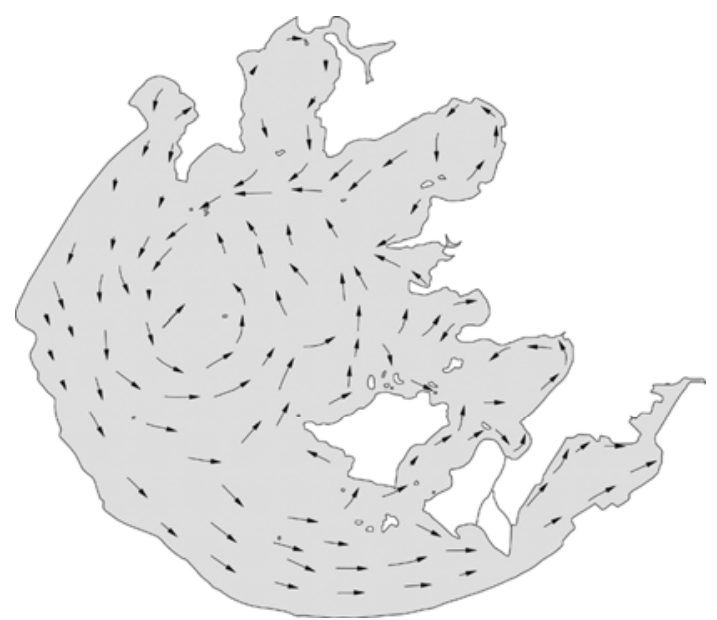

Figure 10 Prevailing lake currents in summer for the Taihu Lake [25]. southern parts of the lake, where the hard loess stratum (U2) is exposed. Beneath the lacustrine sediments are palaeo-riverways (Figures 6 and 7) and depressions with different depths (Figure 8). The palaeo-riverways were mainly observed in the western part of the lake, with various widths and depths. Some parts of them penetrate the hard loess stratum to even lower strata, and are probably connected with modern inflowing riverways. For example, the width is as much as $300 \mathrm{~m}$ for the palaeo-riverways near the Dapu Estuary (Figure 6). The palaeo-riverways stretch mostly from south to north, inconsistent with the results of Sun and $\mathrm{Wu}$ [1] who indicated that the palaeo-riverways are directed mostly from east to west. On the one hand, this contradiction may be due to the different arrangements of the survey lines. On the other hand, this discrepancy highlights the complexity of the directions of the palaeo-riverways. With changing depths, the depressions were primarily distributed in the eastern and southern parts of Taihu Lake, with most not penetrating through the hard loess stratum. Both the palaeo-riverways and the depressions were overlain by lacustrine sediments. Indeed, the basin of Taihu Lake once was entirely covered with loess after a marine regression $[1,9,23]$. Thus, the presence of the palaeo-riverways and depressions provide evidence for erosion of the loess stratum after sedimentation.

\subsection{Spatial distribution of lacustrine sediments of Taihu Lake and its relationship to eutrophication of lake water}

Very severe eutrophication (indicated by the very high TN and TP concentrations in the lake water) and frequent outbreaks of algal blooms [7,26] are observed in the northwestern (including Zhushan and Meiliang bays) and western parts of Taihu Lake. Figure 11 illustrates the contour map of the TN and TP concentrations in the overlying water, based on data from 40 sites within the lake. These data show much higher TN and TP concentrations for western and northwestern parts of the lake, and much lower concentrations for the central, eastern and southern parts of the lake. This pattern is consistent with the sediment distribution of the lake, biased to the northwestern part of the lake. It has been shown that the lacustrine sediments serve as both the sink and source for nutrients in the lake water. The inlet polluted rivers usually supply plenty of nutrients to a lake, with most of them settling in lake water. However, a considerable proportion of nutrients are deposited from the lake water into the sediments, making it a sink for nutrients. The outbreaks of algal blooms generally consume a great deal of nutrients from the lake water, which may not necessarily result in the lowering of TN and TP concentrations. This is because the abundant $\mathrm{N}$ and $\mathrm{P}$ in the sediments form an important internal source for nutrients, which release plenty of $\mathrm{N}$ and $\mathrm{P}$ to the lake water, especially when the sediment is disturbed by wind-driven waves. Based on Ruban et al. 

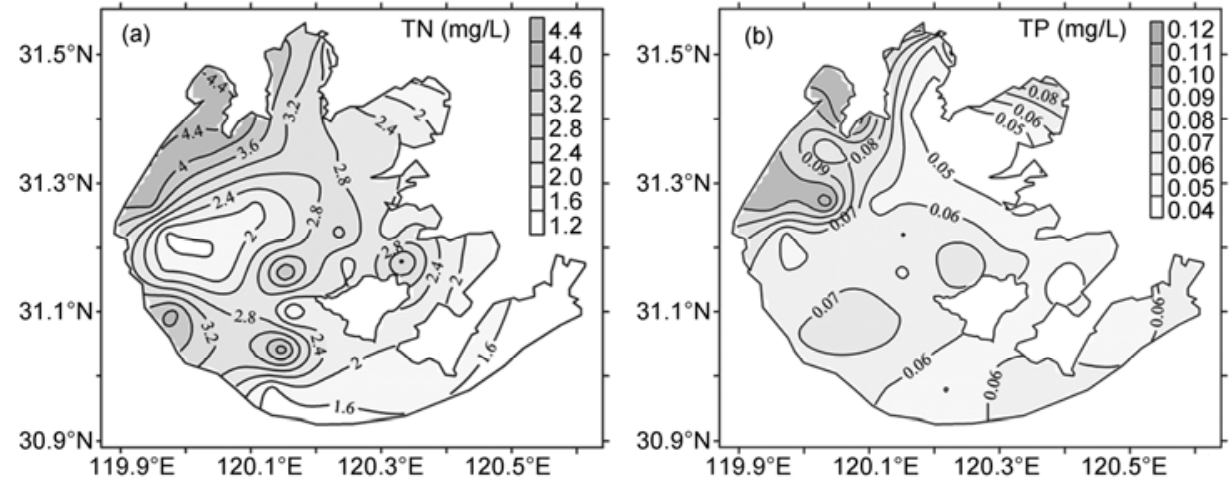

Figure 11 Contour plots of nutrient (TN (a) and TP (b)) concentrations in Taihu Lake.

[27], when affected by physical, chemical and biological processes, the nutrients buried in the lacustrine sediments usually can be released to the overlying lake water through a concentration gradient. This normally results in an increase in nutrient concentrations of the overlying lake water. Overall, exchanges of nutrients between the sediment and overlying lake water usually exert great influence on the eutrophication processes of shallow lakes. In addition, the coupling effects of extrinsic and intrinsic pollution also contribute to the severe eutrophication that takes place in the northwestern part of Taihu Lake.

\section{Conclusions}

A geophysical survey was carried out for the sediment of Taihu Lake, using the StrataBox ${ }^{\mathrm{TM}}$ Marine Geophysical Instrument. Results show that the upper $10-\mathrm{m}$ of sediments are laminated sediments, which can be further classified into two stratal types (i.e. lacustrine sediment stratum and underlying hard loess stratum). The contact between these two strata was not continuous, and parts were absent in the lake basin. The lacustrine sediments mainly were irregularly distributed over the lake basin in areas along the western banks, to the northwest of the Xishan Mountains and in the northern bays. These sediments were scattered across the rest of the lake basin, where outcrops of the hard loess were present. Spatial distribution patterns of lacustrine sediments in Taihu Lake are primarily influenced by sedimentation in the river estuary, as well as the hydrodynamics of lake currents.

We initially used the StrataBox ${ }^{\mathrm{TM}}$ Marine Geophysical Instrument to survey sediments of shallow Taihu Lake. However, for such a large lake, the sediment distribution is very complex and further stratigraphic research is needed. More sedimentary cores throughout Taihu Lake will facilitate further correlations with our geophysical data.

The authors are grateful to Chen Wankang of the Wuxi Institute of Archaeology for providing the stratigraphic data of outcrop sections in Yao Bay. We also thank Meng Xianghua and Zhang Yong for their help with field work. This work was supported by the Knowledge Innovation Program of the Chinese Academy of Sciences (KZCX1-YW-14-5) and the Natural Science Foundation of Jiangsu Province (BK2008055).

1 Sun S C, Huang Y P. Taihu Lake (in Chinese). Beijing: Ocean Press, 1993

$2 \mathrm{Xu} \mathrm{P}$ Z, Qin B Q. Water quantity and pollutant fluxes of the surrounding rivers of Lake Taihu during the hydrological year of 2001-2002 (in Chinese). J Lake Sci, 2005, 17: 213-218

3 Rydin E. Potentially mobile phosphorus in Lake Erken sediment. Wat Res, 2000, 34: 2037-2042

4 Qin B Q, Hu W P, Gao G, et al. Dynamics of sediment resuspension and the conceptual schema of nutrient release in the large shallow Lake Taihu, China. Chinese Sci Bull, 2004, 49: 54-64

5 Fan C X, Zhang L, Qin B Q, et al. Estimation on dynamic release of phosphorus from wind-induced suspended particulate matter in Lake Taihu. Sci China Ser D-Earth Sci, 2004, 47: 710-719

6 Zhu G W, Qin B Q, Gao G. Direct evidence of phosphorus outbreak release from sediment to overlying water in a large shallow lake caused by strong wind wave disturbance. Chinese Sci Bull, 2005, 50: $577-582$

7 Nanjing Institute of Geography and Limnology, Chinese Academy of Sciences (NIGLAS). On the cause of cyanophyta and pollution in water intake area and emergency measures in Meiliang Bay, Lake Taihu in 2007 (in Chinese). J Lake Sci, 2007, 19: 357-358

8 Zhu G W. Eutrophic status and causing factors for a large, shallow and subtropical Lake Taihu, China (in Chinese). J Lake Sci, 2008, 20: 21-26

9 Sun S C, Wu Y F. Formation and evolution of Taihu Lake and modern sedimentation (in Chinese). Sci China Ser B, 1987, 12: 13291339

10 Fan C X, Liu YB, Cheng H. Approach on estimating storage sludge in Lake Taihu and its distributing characteristics (in Chinese). Shanghai Environ Sci, 2000, 19: 72-75

11 Jia G H, Yuan H Z. Application and practice of Holand SILAS subbottom sediment characterization system in Taihu Lake sediment measurment (in Chinese). Water Cons Sci Tech Econ 2005, 11: 521-523

12 Moreno-Amich R, Garcia-Berthou E. A new bathymetric map based on echo-sounding and morphometrical characterization of the Lake of Banyoles (NE-Spain). Hydrobiologia, 1989, 185: 83-90

13 Sindhu B, Suresh I, Unnikrishnan A S, et al. Improved bathymetric datasets for the shallow water regions in the Indian Ocean. J Earth Syst Sci, 2007, 116: 261-274

14 Wang J, Wang Y J, Liu J L, et al. Evolution of sedimentary environment in Taihu Lake during the last 16000 years (in Chinese). Acta Palaeontol Sin, 1996, 35: 213-223

$15 \mathrm{Xu} \mathrm{X} \mathrm{M,} \mathrm{William,} \mathrm{Chang} \mathrm{Y} \mathrm{B,} \mathrm{et} \mathrm{al.} \mathrm{Change} \mathrm{in} \mathrm{vegetation} \mathrm{and} \mathrm{cli-}$ mate in the Taihu Lake basin during the last 11000 years (in Chinese). Acta Palaeontol Sin, 1996, 35: 175-186 
16 William, Chang Y B, Liu J L. The origin and evolution of Taihu Lake: Since the last 11000 year (in Chinese). Acta Palaeontol Sin, 1996, 35: 129-135

17 Zhu G W, Qin B Q, Gao G, et al. Accumulation characteristics of heavy Metals in the Sediments of Lake Taihu, China (in Chinese). J Lake Sci, 2005, 17: 143-150

18 Liu E F, Shen J, Zhu Y X, et al. Source Analysis of heavy metals in surface sediment of Lake Taihu (in Chinese). J Lake Sci, 2004, 16: 113-119

19 Yu L Z, Xu Y, Xu S Y. Paleoenvironmental implication of magnetic measurements on sediment cores from Taihu Lake, east China (in Chinese). J Lake Sci, 1995, 7: 141-150

20 Søndergaard M, Jensen J P, Jeppesen E. Role of sediment and internal loading of phosphorus in shallow lakes. Hydrobiologia, 2003, 506-509: 135-145

21 Lijklema L, Koelmans A, Portielje R. Water quality impacts of sediment pollution and the role of early diagenesis. Water Sci Technol, 1993, 28: 1-12

22 Qin B Q, Zhu G W, Zhang L, et al. Estimation of internal nutrient re- lease in large shallow Lake Taihu, China. Sci China Ser D-Earth Sci, 2006, 49 (Suppl I): 38-50

23 William, Chang Y B, Xu X M, et al. Evolution in Taihu Lake ecosystem as evidence of changes in sediment profiles (in Chinese). J Lake Sci, 1994, 6: 217-226

24 Liu J J, Wu J L. Environmental information of recent 100 years recorded sediments of Dapu area in Taihu Lake (in Chinese). J Palaeogeogr, 2006, 8: 559-564

25 Qin B Q, Hu W P, Chen W M, et al. Studies on the hydrodynamic processes and related factors in Meiliang Bay, northern Taihu Lake, China (in Chinese). J Lake Sci, 2000, 12: 327-334

26 Trolle D, Zhu G W, Hamilton D, et al. The influence of water quality and sediment geochemistry on the horizontal and vertical distribution of phosphorus and nitrogen in sediments of a large, shallow lake. Hydrobiologia, 2009, 627: 31-44

27 Ruban V, Brigault S, Demare D, et al. An investigation of the origin and mobility of phosphorus in freshwater sediments from Bort-LesOrgues Reservoi, France. J Environ Monit, 1999, 1: 403-407

Open Access This article is distributed under the terms of the Creative Commons Attribution License which permits any use, distribution, and reproduction in any medium, provided the original author(s) and source are credited. 